\title{
Transabdominal, a dominant mutant of the Bithorax Complex, produces a sexually dimorphic segmental transformation in Drosophila
}

\author{
Susan E. Celniker and E.B. Lewis \\ Division of Biology, California Institute of Technology, Pasadena, California 91125 USA
}

\begin{abstract}
Transabdominal (Tab), a dominant mutation in the Bithorax Complex (BX-C) of Drosophila, creates a sexually dimorphic pattern of segmental transformation that has complete penetrance and expressivity. Specific regions within the notum of the second thoracic segment (T2) are transformed into abdominal-like cuticle; thus, the $T a b /+$ notum has sets of short stripes that are black in males and only bordered with black in females. Also, $\mathbf{T a b} /+$ abdominal tergites, A1-A6, inclusive, have small patches of A7-like tergite cuticle. Tab is inseparable from an $89 \mathrm{E} / 90 \mathrm{D}$ inversion, whose DNA breakpoint in $89 \mathrm{E}$ is at $+188 \mathrm{~kb}$ in the infra-abdominal-8 (iab-8) region of the BX-C. When probed with a pupal cDNA from the iab-7 region, labeling above background was not detected in wild-type wing discs but was detected in, and confined to, the notal region of $T a b /+$ wing discs. The $T a b /+$ phenotype is assumed to result from cis-overexpression of iab-7 in localized regions of segments T2-A6, inclusive.
\end{abstract}

[Key Words: Bithorax Complex; cis-regulation; homeotic loci; Drosophila; imaginal discs; sexual dimorphism] Received December 17, 1986; revised version received and accepted January 14, 1987.

There is now a considerable body of evidence suggesting that Drosophila embryonic development is controlled by a heirarchy of sequentially activated genes. The spatial coordinates of the egg are determined early in oogenesis by the maternal-effect genes (Nüsslein-Volhard 1979), followed by activation or derepression of two types of zygotic genes: (1) segmentation genes, including the gap, segment-polarity, and pair-rule genes that control the number and polarity of the segments (NüssleinVolhard and Wieschaus 1980), and (2) homeotic genes that control segmental identity. The majority of the latter genes appear to reside in two major gene complexes, the Antennapedia Complex (ANT-C) (Kaufman et al. 1980; Scott et al. 1983; Garber et al. 1983) and the Bithorax Complex (BX-C) (Lewis 1978). The derepression of these latter two complexes seems to be under the control of a number of trans-regulatory genes such as Polycomb (Pc) (Lewis 1978) and extra sexcombs (esc) (Struhl 1981).

The BX-C contains the genes necessary for the development of the third thoracic segment (T3) and at least the first eight abdominal segments (Lewis 1978). The complex has been cloned and covers over $300 \mathrm{~kb}$ of DNA (Bender et al. 1983a; Karch et al. 1985). Studies of the effects in the adult fly of recessive loss-of-function and dominant gain-of-function mutants have shown that the BX-C genes accomplish intersegmental transformations in which a given segment, or portion thereof, achieves a level of development that is one step more advanced than that of the immediately anterior segment. Thus, in the case of the abdominal segments that are of primary concern in this paper, $i a b-7^{+}$controls a transformation of the seventh abdominal segment, A7, from a sixth abdominal level of development, LA6, to a seventh level, LA7. Similarly, in adults $i a b-8^{+}$controls a transformation of A8 from LA7 to LA8. In keeping with these interpretations of the wild-type functions of $i a b-7$ and $i a b-8$ are the effects of recessive loss-of-function mutants. Thus, iab-7 mutants have as their primary effect in the adult the following transformation: In the case of the homozygous iab-7 mutant female, a large tergite resembling that of A6 (or A5) arises in place of the normally rudimentary A7 tergite of that sex; in the case of the iab-7 homozygous male, a large seventh tergite resembling that of A6 (or A5) arises, even though the male normally lacks an A7 tergite. Recessive loss-of-function mutants of $i a b-8$ show as their primary effect in adults, reduction or absence of genitalia as the result of defects in the genital discs which are derived from segments A8, $\mathrm{A} 9$, and A10. Initial descriptions of the adult and ventral embryonic $i a b-7$ and $i a b-8$ recessive phenotypes are described in Karch et al. (1985) and a further characterization of the dorsal and ventral embryonic phenotypes is given below. [Sanchez-Herrero et al. (1985) and Tiong et al. (1985) have described a group of mutants they call $A b d-B$ mutants, some of which are like iab-7 mutants and some like $i a b-8$ mutants.] Moreover, not only have DNA regions been identified within the BX-C that cor- 


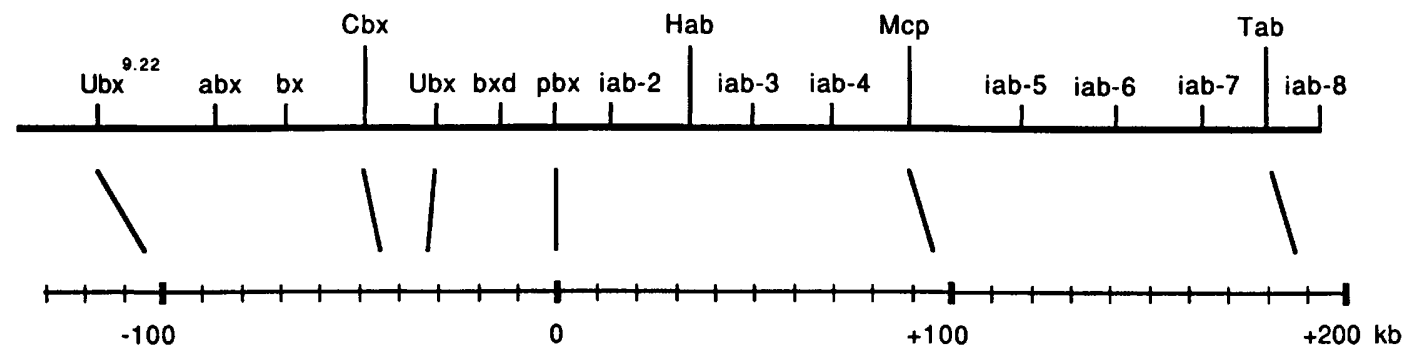

Figure 1. A correlation of the genetic and molecular maps of the BX-C. The upper line represents the genetic map. The lowest row of symbols is loss-of-function mutants, and the top row is dominant gain-of-function mutants. Abbreviations: Ubx, Ultrabithorax; abx, anterobithorax; $b x$, bithorax; $C b x$, Contrabithorax; $b x d$, bithoraxoid; pbx, postbithorax; iab, infra-abdominal; Hab, Hyperabdominal; Mcp, Miscadastral pigmentation; Tab, Transabdominal. The lower line represents the molecular map. The approximate location, in kilobases $(\mathrm{kb})$, of a few key loci is indicated in relation to that of $p b x$, which is placed at 0.0 since it was the start of the DNA walk (Bender et al. 1983a).

respond to each such segmental transformation from $\mathrm{T} 3$ to $A 8$, inclusive, but also the order of such regions in the chromosome parallels the order of the segments along the body axis. In addition to recessive loss-of-function mutants, there is a much rarer class of dominant gainof-function mutants, such as Contrabithorax $(C b x)$, which tend to result in transformations of a given segment toward an immediately posterior one.

Still more rare are segmental transformations that span many segments; namely, SGA-62, which has rudiments of an A6-like tergite in the head region (Awad et al. 1981), and tumorous head (tuh), which has either rudiments of tergite-like tissue (Postlethwaite et al. 1972) or of genitalia-like tissue in the head region (Kuhn et al. 1981), depending upon complex genetic background factors. Transabdominal $(T a b)$, which we describe in this paper, is unique among such mutants. It not only transforms specific regions of the thorax into sexually dimorphic abdominal-like cuticle, but in doing so has complete penetrance and expressivity, whereas $S G A-62$ and tuh tend to have poor penetrance and poor expressivity. We present cytogenetic and molecular evidence that this pattern results from a cis-overexpression of iab-7 in many segments anterior to $\mathrm{A} 7$ and in a patternrestricted (possibly clonal) manner.

\section{Results}

The current status of the map of the BX-C and references for mutant symbols is shown in Figure 1. Transabdominal $(T a b)$ is a dominant mutant that alters the cuticular pattern of the notum of $\mathrm{T} 2$ (Celniker and Lewis 1984) and male tergites, A1-A5, inclusive, and female tergites A1-A6, inclusive. Tab was induced with X-rays on a $p^{p} M c p S a b$ chromosome and is associated with a small inversion, In(3R)Tab, having one breakpoint within the BX-C in $89 \mathrm{E}$ and the other outside the BX-C in $90 \mathrm{D}$. The mutant is $100 \%$ penetrant and has complete expressivity of the thoracic component of the phenotype.

\section{Dominant phenotype of Tab}

The wild-type adult thorax is light tan in color and is covered with very tiny hairs or trichomes. The dorsal surface, or notum, has in addition regular rows of small bristles, or microchaetes, and 15 pairs of larger bristles or macrochaetes (e.g., see Bryant 1978). In Tab/ + flies (Fig. 2) the notum bears two sets of longitudinal stripes that are partially devoid of trichomes (Fig. 3). In Tab/ + males both sets of stripes are solidly pigmented black. On the other hand, in $\mathrm{Tab} /+$ females the inner set is lighter in color than the rest of the notum and devoid of black pigment, while the outer set is bordered with black pigment along the edge nearest the midline. The inner set of stripes in some $\mathrm{Tab} /+$ females has a small patch of black pigment at the posterior margin. In both sexes, the posterior end of the outer set of stripes forms a raised vortex with whirled microchaetes. The outer set of stripes is complex in that it is interrupted in the

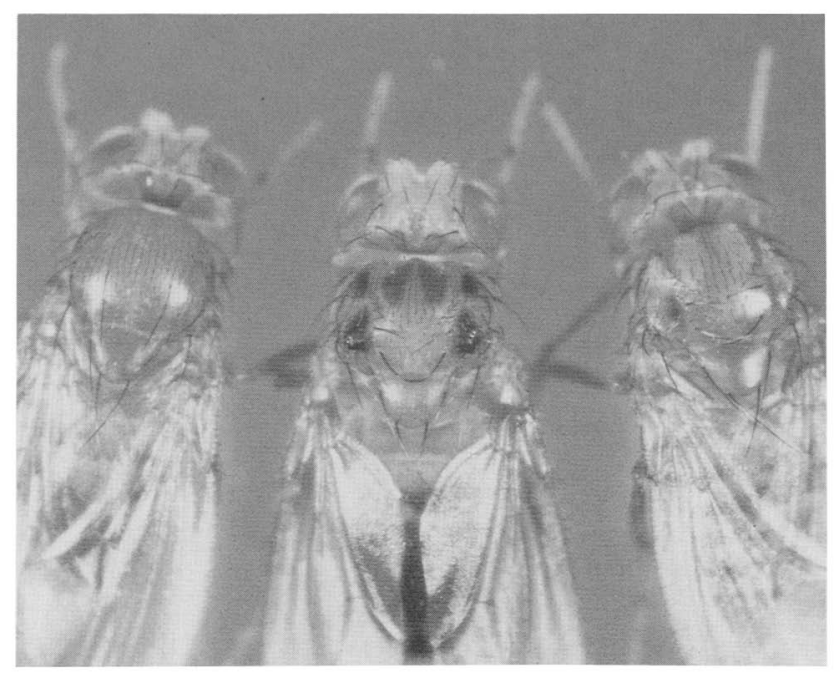

Figure 2. Thoracic pigmentation pattern of Tab. A photograph of adult wild-type and Tab/ + flies. (Left to right) Wild-type (Canton S) male; $\mathrm{Tab} /+$ male showing two sets of solidly black-pigmented notal stripes, the inner set extending from the neck region posteriorly for one-half the length of the notum, and the outer set extending two-thirds the length of the notum and ending in a vortex lateral to the dorsocentral region; and a $T a b /+$ female showing identically located sets of stripes as in the male, but with the inner set devoid of black pigment and the outer set only bordered with black pigment along the edge nearest the midline. 


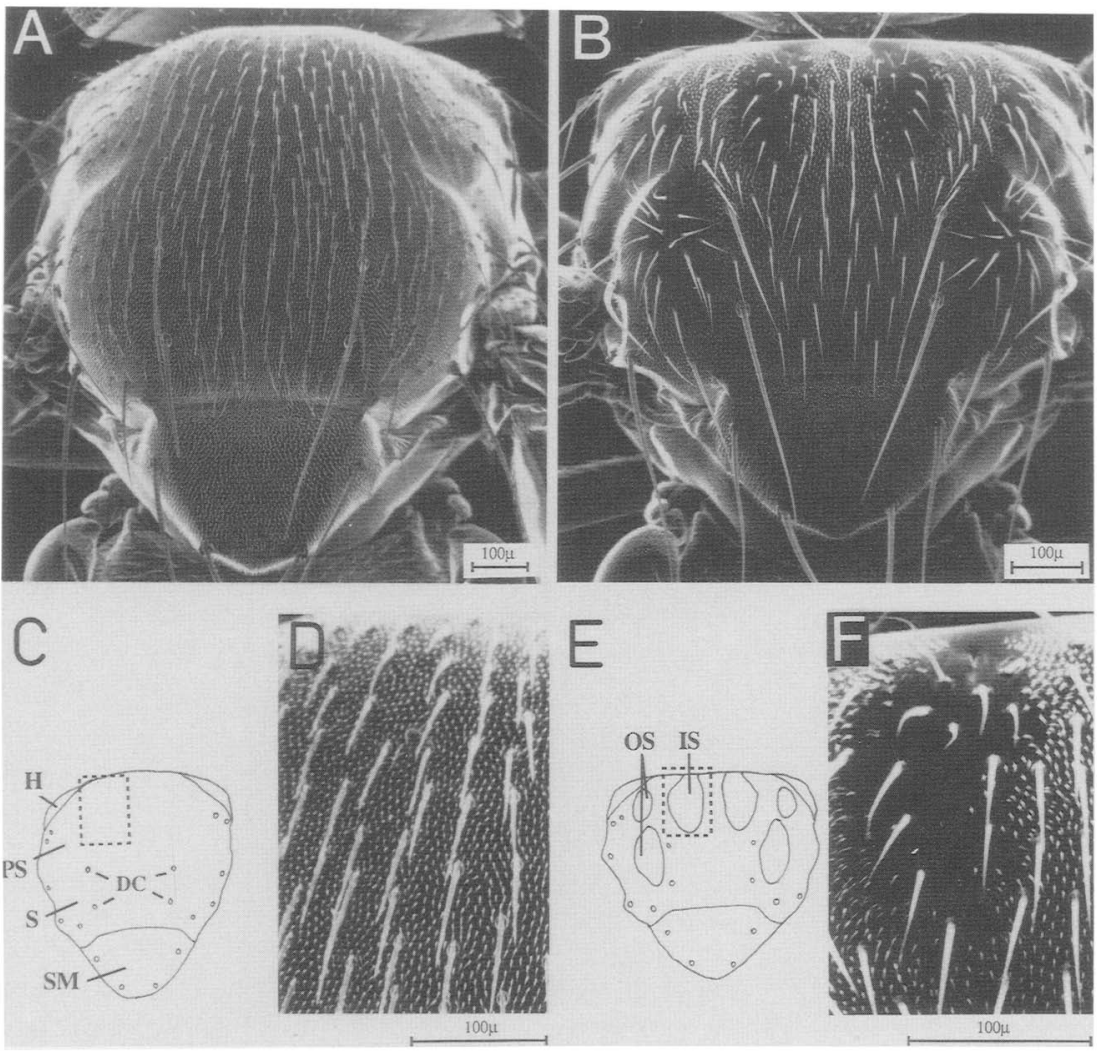

Figure 3. Adult thoracic cuticular phenotype of Tab. Scanning electron micrographs and diagrams of the dorsal surface of the notum from wild-type and Tab mutant flies. $(A)$ The wild-type notum shows a uniform distribution of microchaetes and trichomes. $(B)$ The $\mathrm{Tab} /+$ notum shows two sets of stripes on either side of the midline; the microchaetes in these stripes are abnormally oriented. $(C) \mathrm{A}$ diagram of the wild-type notum shown in $A$. (H) Humerus; (PS) prescutum; (S) scutum; (SM) scutellum; (DC) dorsocentral bristles. The small open circles represent the sites of macrochaetes (for identification see, e.g., Bryant 1975). (D) An enlargement of the portion of the prescutum outlined by the hatched line in diagram $C$ to show the trichome pattern. $(E)$ A diagram of the Tab notum shown in $B$. The elliptically shaped regions outlined in the diagram represent the two sets of Tab stripes; namely OS (outer set) and IS (inner set). (F) An enlargement of the portion of the prescutum outlined by the hatched line in diagram $E$ to show the absence of trichomes and the abnormal microchaete pattern.

middle; alternatively, that set can be described as consisting of two short stripes with the more posterior one bearing the raised vortex. The notal stripes presumably correspond to the cuticle of tergite A7, or A6, since in wild-type and $T a b /+$ animals only those tergites are largely devoid of trichomes (Fig. 4).

In the wild-type female the tergites are light tan in color and bear a band of black pigment along the posterior margin. In the wild-type male, tergites $\mathrm{Al}-\mathrm{A} 4$, inclusive, resemble those of the female, while tergites A5 and $\mathrm{A} 6$ are completely covered with black pigment. Since the Tab chromosome contains two other dominant mutations, $M c p$ and $S a b$, which cause A3 and A4 to be partially transformed toward A5, the A3 and A4 tergites tend to be pigmented black in $M c p S a b T a b /+$ males. However, $D p(3 ; 1) 68 ; M c p S a b T a b /+$ males $(D p-68$ is a duplication that includes the entire BX-C) occasionally show virtually normal male-type pigmentation on A4 and A5 tergites. Since such males retain the strongly black-pigmented notal stripes, it is unlikely that $M c p$ and $S a b$ are playing any role in determining the pattern of sexual dimorphism in the Tab thorax. Because the inversion associated with $T a b$ strongly reduces recombination in its vicinity, removal of $M c p$ and $S a b$ from the $T a b$ chromosome by crossing over is not practical.

$\mathrm{Tab} /$ + animals show small trichomeless patches in the tergites of A1-A5, inclusive (Fig. 5). Since the A6 tergite is devoid of trichomes in wild-type as well as in $T a b /+$ animals, except along the anterior and lateral edges of that tergite, $\mathrm{Tab} /+$ patches in A6 are only readily identifiable in females on the basis of pigmentation. Thus, in such females small black-pigmented trichomeless patches of presumptive A7-like cuticle are occasionally seen in A6.

The frequency of trichomeless patches has been determined omitting the tergite of $\mathrm{A} 6$ (and also that of $\mathrm{Al}$, since the latter is smaller and frequently tends to be damaged in preparing whole mounts of abdomens). Among six $\mathrm{Tab} /+$ males and six $\mathrm{Tab} /+$ females scored over tergites A2-A5, inclusive, a total of 35 and 46 trichomeless patches, respectively, were found among the 24 male tergites and 24 female tergites scored, or a mean of 1.5 and 1.9 patches per tergite, respectively; the 


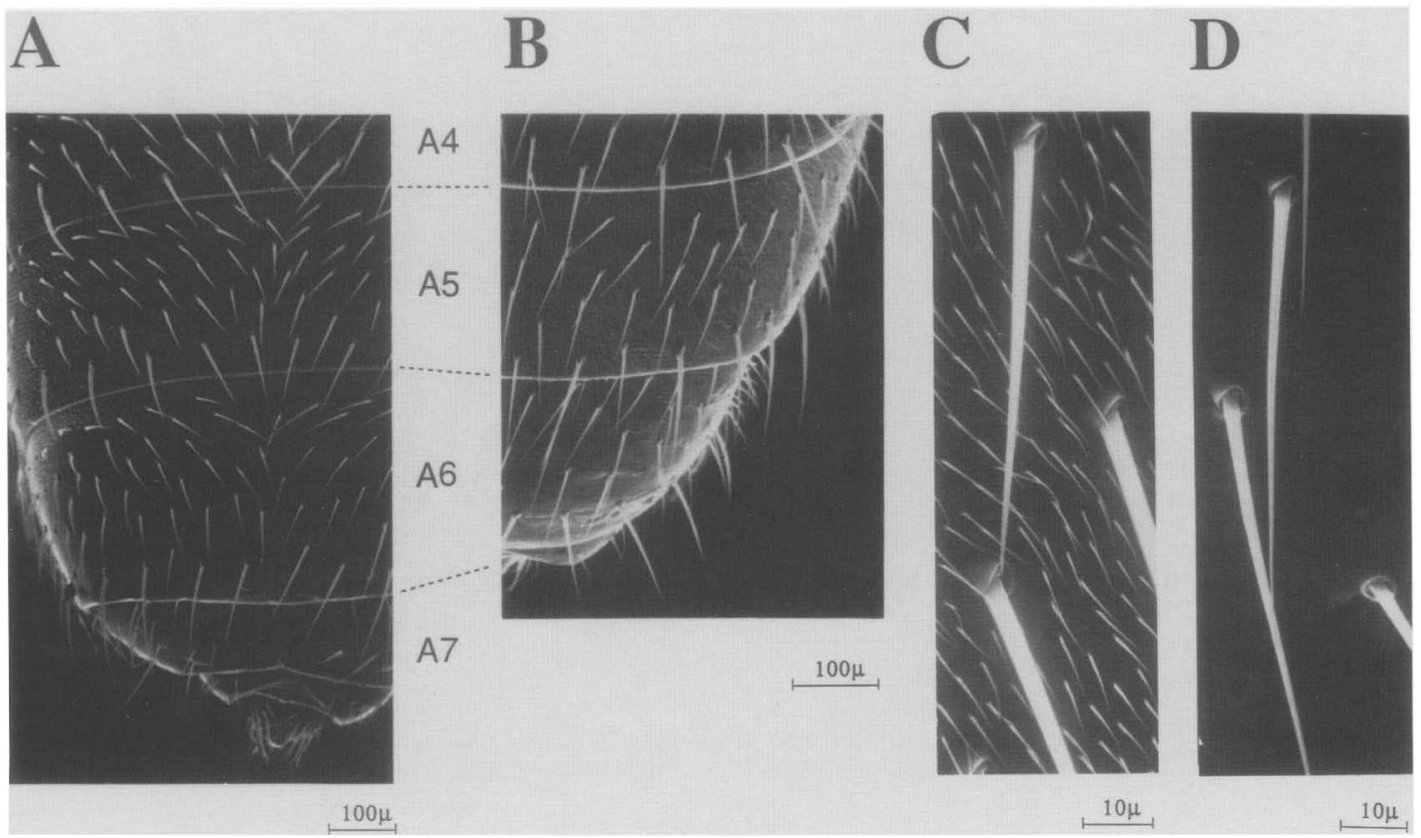

Figure 4. Cuticular $i a b-7$ and wild-type phenotypes of adult abdominal segments. Scanning electron micrographs of a portion of the dorsal surface or tergite of the male adult abdomen. (A) Heterozygous iab-7D6/ + the + chromosome also carries the TMl balancer see Lindsley and Grell 1968) male showing portions of the tergites of abdominal segments A4-A7 inclusive. The pattern of bristles and trichomes on A4-A6 is similar to the corresponding patterns of wild-type (see $B, C$, and $D$ ). The rudimentary tergite on $A 7$ has patches of microchaetes, but no trichomes. $(B)$ Wild-type (Canton S) male showing portions of A4, A5, and A6 tergites. There is a single row of macrochaetes along the posterior edge of each tergite and three or four rows of microchaetes on A5 and A6. Trichomes are present on $\mathrm{A} 4$ and $\mathrm{A} 5$ but absent in the central area of $\mathrm{A} 6$. (C) Portion of wild-type A5 tergite enlarged to show the presence and pattern of trichomes. (D) Portion of wild-type A6 tergite enlarged to show the absence of trichomes.

number of tergites lacking such patches was three and the number having two or more patches was 31 .

In $\mathrm{Tab} /+$ animals the lateral edges of tergites A $1-\mathrm{A} 6$, inclusive, show variable degrees of erosion of the cuticle. This erosion appears to be a transformation toward an A7-like tergite inasmuch as that tergite is normally reduced in size compared with that of A6.

Although $T a b /+$ females lay eggs and the males have motile sperm, both sexes are sterile, or virtually so. The sterility is rescued by adding duplications of the BX-C, such as $D p(3 ; 1) 68$. Although such duplications suppress the dominant sterility of $\mathrm{Tab} /+$, they do not suppress its abnormal morphology in the cuticle of the thorax and abdomen.

\section{Recessive phenotype of Tab}

A recessive $T a b$ phenotype can be detected in adults that are heterozygotes for $T a b$ and loss-of-function mutants of $i a b-8$. Two such mutants, Ultrabdominal ${ }^{1}\left(U a b^{1}\right)$ and tumorous-head ${ }^{3}\left(t^{3} h^{3}\right)$ were first recognized because of their dominant phenotypes and only later found to be recessive mutants of $i a b-8$. (For a description of the molecular basis of $U a b^{1}$ and tuh, see Karch et al. 1985.) $T a b / i a b-8^{U a b 1}$ and $T a b / i a b-8^{\text {tuh-3 }}$ heterozygotes both survive as adults. They lack internal and external genitalia and analia in both sexes; in males, lack of genital ducts results in their having unattached testes which then fail to undergo coiling. When $T a b$ is heterozygous with weak iab-7 mutants $(D 6, D 14, D 15)$ there is a rotation of genitalia in the males that suggests a weak cis-inactivation of $i a b-8$ in the $i a b-7$ mutant chromosome. When $T a b$ is heterozygous with $i a b-7^{65}$ both sexes lack genitalia. $i a b-7^{65}$ is possibly a very weak $i a b-7$ mutant with a strong cis-inactivation of $i a b-8$ (Karch et al. 1985), but since, in fact, it is an extreme loss of function of $i a b-8$ it is more likely an iab-8 than an iab-7 mutant (Fig. 6D). $i a b-7^{65}$ is associated with a translocation with breakpoints in $89 \mathrm{E}$ and 41 . A DNA breakpoint was located within the BX-C at $+165 \mathrm{~kb}$, which places it in a region as yet poorly characterized that extends from the distal portion of $i a b-7$ to the proximal region of $i a b-8$ (Karch et al. 1985).

Tab/Df-P14 heterozygotes (where $D f-P 14$ is a deficiency for $90 \mathrm{C}-91 \mathrm{~A}$ ) are lethal in the late embryonic stage. They lack any obvious cuticular transformations, whereas heterozygotes involving $T a b$ and deficiencies for either the entire BX-C (Df-P $P$ ) or the distal region (Df-C4) thereof are not only lethal in the embryonic stage but also show a strong cuticular transformation of A8 toward A7 (Karch et al. 1985). Thus, as shown in Figure 6C, Tab/Df-P9 embryos have dorsal triangles in the posterior region of $\mathrm{A} 7$; transformation of dorsal hairs of anterior A8 toward the pattern in A7, abnormal posterior spiracles, and a rudimentary ninth row of denticles. This row presumably corresponds to the anterior row of denticles found in the ventral setal bands of segments A2-A8, inclusive, of wild type, and from the work of Szabad et al. (1979), it probably belongs to the posterior compartment of the segment ahead. Hence, the ninth 


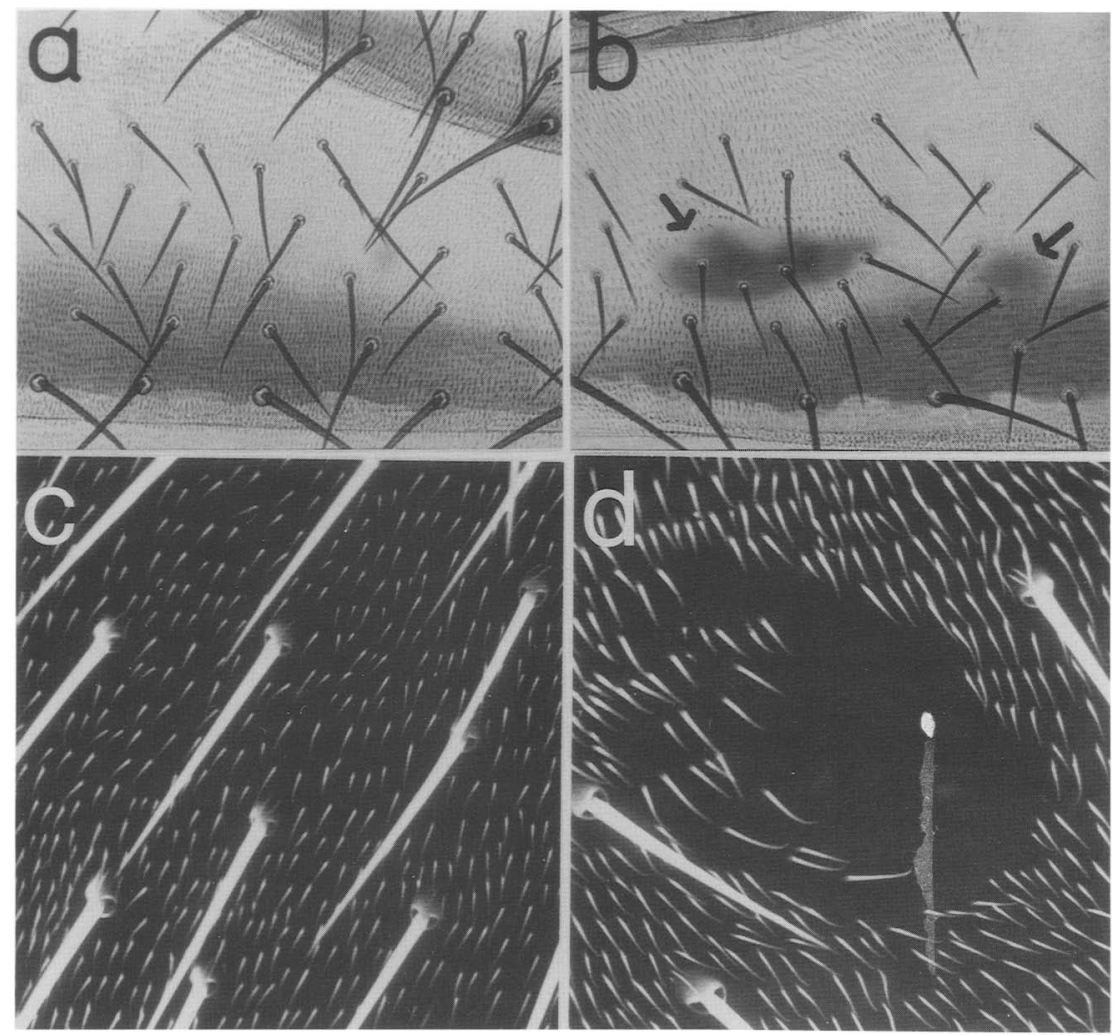

Figure 5. Abdominal cuticular phenotype of Tab. $\{a\}$ Portion of an A.3 hemitergite from a wild-type (Canton S) female. A band of black pigment identifies the posterior one-third of the tergite. (b) Portion of an A3 hemitergite from a Tab/ + female showing $\mid$ arrows $\mid$ two patches of cuticle that are pigmented black and devoid of trichomes. Ic| SEM of a portion of the third hemitergite from a wild-type (Canton S) male showing the wild-type trichome pattern. (d) SEM of a portion of the third hemitergite of a Tab/+ male showing a patch of abdominal tissue devoid of trichomes.

row is shown as belonging to posterior A8. Although such animals have the ventral setal band of A8 partially transformed toward that of $\mathrm{A} 7$, that band is also transformed to about the same extent in the control animals, $D f-P 9 /+($ Fig. $6 \mathrm{~B})$, indicating that the iab-8 function, like most other genes in the complex, is not entirely haplo-sufficient.

The recessive lethal $T a b$ phenotype seen in A8 of $T a b$ homozygotes and hemizygotes is also found in heterozygotes between $T a b$ and strong iab-7 mutants $(297,380$, $D 3$, and $D 16$ ). Such heterozygotes are lethal in the late embryonic stage and closely resemble Tab/Df-P9 animals, i.e., they have a strong transformation of $\mathrm{A} 8$ toward A7, and a ninth setal band consisting of only a single row of denticles.

In embryonic and larval stages the $i a b$ transformations behave for the most part in a parasegmental (MartinezArias and Lawrence 1985) rather than segmental manner. Correspondences between segments and parasegments are shown in Figure 6 for A6, A7, and A8, the segments of primary concern. In the embryo, a loss of function in iab-8 can be said to transform parasegment 13 (PS13) toward PS12; however, the presence of the ninth row of denticles in posterior A8 without a transformation of the remaining portion of the ventral setal band in the ninth segment indicates that the anterior part of PS14 transforms toward the corresponding part of
PS13, hence the latter can be better described as part of a segmental transformation of A8 toward A7. It seems likely that there are genes for controlling the partial suppression of A9 and A10, but they have not yet been located, nor have their segmental or parasegmental transformations been determined.

\section{Revertants of $\mathrm{Tab}$}

To analyze which end of the inversion associated with $T a b$ might be responsible for the dominant $T a b$ phenotype, we have induced revertants of the dominant $T a b$ phenotype with X-rays. Roughly $80,000 \mathrm{Tab}$ chromosomes were irradiated at a dose of $4000 \mathrm{r}$ units and 12 complete revertants of the dominant Tab phenotype were recovered. Eight of the 12 revertants are associated with a new cytologically visible rearrangement superimposed on the original $T a b$ inversion (Table 1). In every case the proximal junction (89E) of the inversion was rearranged rather than the distal junction (90D).

When hemizygous, each of the revertants shows a stronger transformation of the eighth ventral setal band toward that of the seventh than does the Tab hemizygote $(T a b / D f-P 9)$. Tab revertants fall into three classes based on their phenotypes when hemizygous. Class I revertants (R96, R100, R107, R111, R114, R175, and $R 185)$ when hemizygous show abnormal posterior spiracles 


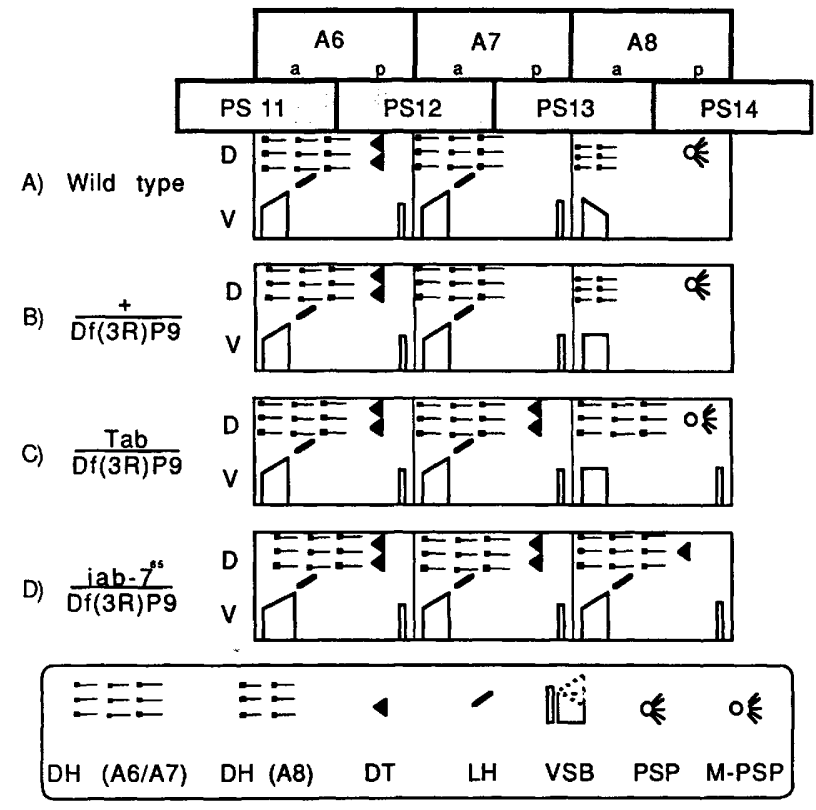

Figure 6. Diagram of wild-type and BX-C mutant phenotypes detectable in abdominal segments A6, A7, and A8 of the firstinstar larva. Dorsal and ventral aspects of abdominal segments A6, A7, and A8 are schematically presented. All drawings are based on whole mounts of animals examined with phase-contrast microscopy. Abbreviations: (DH) dorsal hairs; (DT) dorsal triangles; (LH) lateral hair; (VSB) ventral setal band; (PSP) posterior spiracle; $(\mathrm{M}-\mathrm{PSP})$ malformed posterior spiracle; (a) anterior; (p) posterior; (D) dorsal; (V) ventral. Omitted are abdominal segments $\mathrm{A} 9$ and $\mathrm{A} 10$ and structures from abdominal segment $\mathrm{A} 8$, whose segmental location is unclear, namely, the filzkorper, the caudal sense organs, dorsal hairs associated with the posterior spiracle, and dorsal hairs posterior to the posterior spiracle. $(A)$ Wild type. $(B)$ Wild-type hemizygote showing similarity to wild-type homozygote, except that the VSB of A8 is broader. $(C)$ $T a b$ hemizygote showing dorsal transformation of $\mathrm{pA} 7$ to $\mathrm{pA} 6$ and $\mathrm{aA} 8$ to $\mathrm{aA7}$; the transformation of $\mathrm{A} 8$ to $\mathrm{A} 7$ does not include the lateral hair; ventrally aA 8 appears similar to aA 8 of the wild-type hemizygote, but the beginning of a ninth ventral setal band appears in pA8; the spiracles are farther apart and their terminal hairs are misplaced. $(D) i a b-7^{65}$ hemizygote showing the complete transformation of $\mathrm{pA} 7$ to $\mathrm{pA6}, \mathrm{aA} 8$ to aA7, and pA8 to apparently an intermediate state between pA6 or pA7. The ventral aspects of all of the above phenotypes are figured in Karch et al. (1985).

and a rudimentary ninth ventral setal band similar to that of Tab hemizygotes (data not shown). Class I revertants correspond to extreme iab-8 mutants. Class II revertants (R89 and $R 82)$ when hemizygous, have $\mathrm{A} 7$ transformed toward A5 or A6, lack posterior spiracles and filzkorper, and have no ninth ventral setal band. Class III $(R 5, R 10$, and $R 75)$ when hemizygous, have in addition to the effects seen in the case of Class II, chitinized plates located just posterior to the ventral setal bands of A8 (data not shown); such plates, which were first seen in $D f-P 9$ homozygotes, are believed to represent rudiments of the mandibular hooks (Lewis 1978). Class II and Class III $T a b$ revertants have embryonic phenotypes that characterize them as weak and strong iab-7 mutants, respectively, as defined in Karch et al. (1985).

\section{DNA analysis of Tab and revertants}

To localize the $T a b$ breakpoint within the BX-C we have used DNA fragments isolated from recombinant DNA clones representative of wild-type BX-C to probe blots of restriction endonuclease-digested genomic DNA from wild-type and from $T a b /+$ flies. The results show that the breakpoint is located on a $1-\mathrm{kb}$ genomic fragment from +187 to +188 (Fig. $7 \mathrm{~A}$ ). The breakpoint was verified by in situ hybridization to salivary gland chromosomes from $\mathrm{Tab} /+$ third-instar larvae; i.e., in nuclei in which the Tab and wild-type chromosomes were not somatically paired, the genomic fragment from +187 to $+188 \mathrm{~kb}$ hybridized to the $89 \mathrm{E} / 90 \mathrm{D}$ and $90 \mathrm{D} / 89 \mathrm{E}$ ends of the Tab inversion, but only to the $89 \mathrm{E}$ region and not the 90D region of the wild-type chromosome (data not shown).

We have constructed a genomic DNA library from $\mathrm{Tab} /$ + flies and isolated and sequenced DNA at the proximal $89 \mathrm{E} / 90 \mathrm{D}$ breakpoint of $\operatorname{In}(3 R) \mathrm{Tab}$. This breakpoint is located at $187.6 \mathrm{~kb}$. We have localized the breakpoints of five of the revertants and find they map (see Table 1 and Fig. 7A) just proximally to the proximal $T a b$ breakpoint of $\operatorname{In}(3 R) T a b$, in a region from +170 to $+187 \mathrm{~kb}$. The revertant breakpoints span $17 \mathrm{~kb}$ of DNA and are distributed within the $i a b-7$ and $i a b-8$ regions.

The cytogenetic data on $T a b$ revertants are consistent with the Tab phenotype being the result of a position effect on the wild-type $i a b-7$ gene. Therefore we have undertaken a molecular analysis of that gene and its transcripts. Regulski et al. (1985) have identified a homeo box that is located at position $+153 \mathrm{~kb}$ in the $i a b-7$ region of the BX-C. Using genomic DNA from

Table 1. Cytological and molecular (DNA) analysis of Tab revertants

\begin{tabular}{llcll}
\hline Class & Mutant & Screen & \multicolumn{1}{c}{ Cytology $^{\mathrm{a}}$} & Position $^{\mathrm{b}}$ \\
\hline I & R96 & 1 & $\mathrm{Tp}(3) 80 ; 89 \mathrm{E}$ & $170-173$ \\
I & R100 & 1 & $\mathrm{~T}(2 ; 3) 37 \mathrm{EF} / 38 \mathrm{~A} ; 89 \mathrm{E}$ & $183-184$ \\
I & R107 & 1 & $\mathrm{In}(3 \mathrm{R}) 89 \mathrm{E} ; 90 \mathrm{~A} \pm$ & $185-187$ \\
I & R111 & 1 & $\mathrm{~T}(\mathrm{Y} ; 3) 89 \mathrm{E}$ & $170-180$ \\
I & R114 & 1 & $\mathrm{~T}(1 ; 3 ; 4) 20 ; 89 \mathrm{E} ; 101$ & $183-184$ \\
I & R175 & 1 & $\mathrm{~T}(1 ; 3) 20 ; 89 \mathrm{E}$ & \\
I & R185 & 1 & $\mathrm{~T}(2 ; 3) 50 \mathrm{D} ; 89 \mathrm{E}$ & \\
II & R89 & 1 & $\mathrm{~T}(\mathrm{Y} ; 3) 89 \mathrm{E}$ & \\
II & R82 & 2 & $\mathrm{Tp}(3) 64 \mathrm{EF}-65 \mathrm{~A} ; 89 \mathrm{E}$ & \\
III & R5 & 1 & NNR & \\
III & R10 & 2 & NNR & \\
III & R75 & 2 & NNR & \\
\hline
\end{tabular}

${ }^{a}$ Revertants of the dominant $T a b$ phenotype were X-ray induced on the chromosome, $\operatorname{In}(3 R) T a b$, and have not been separated from this inversion.

b Refers to the composite restriction map of the bithorax complex (Bender et al. 1983; Karch et al. 1985).

c Recovered as a gonadal mosaic.

d No new rearrangement detectable. 


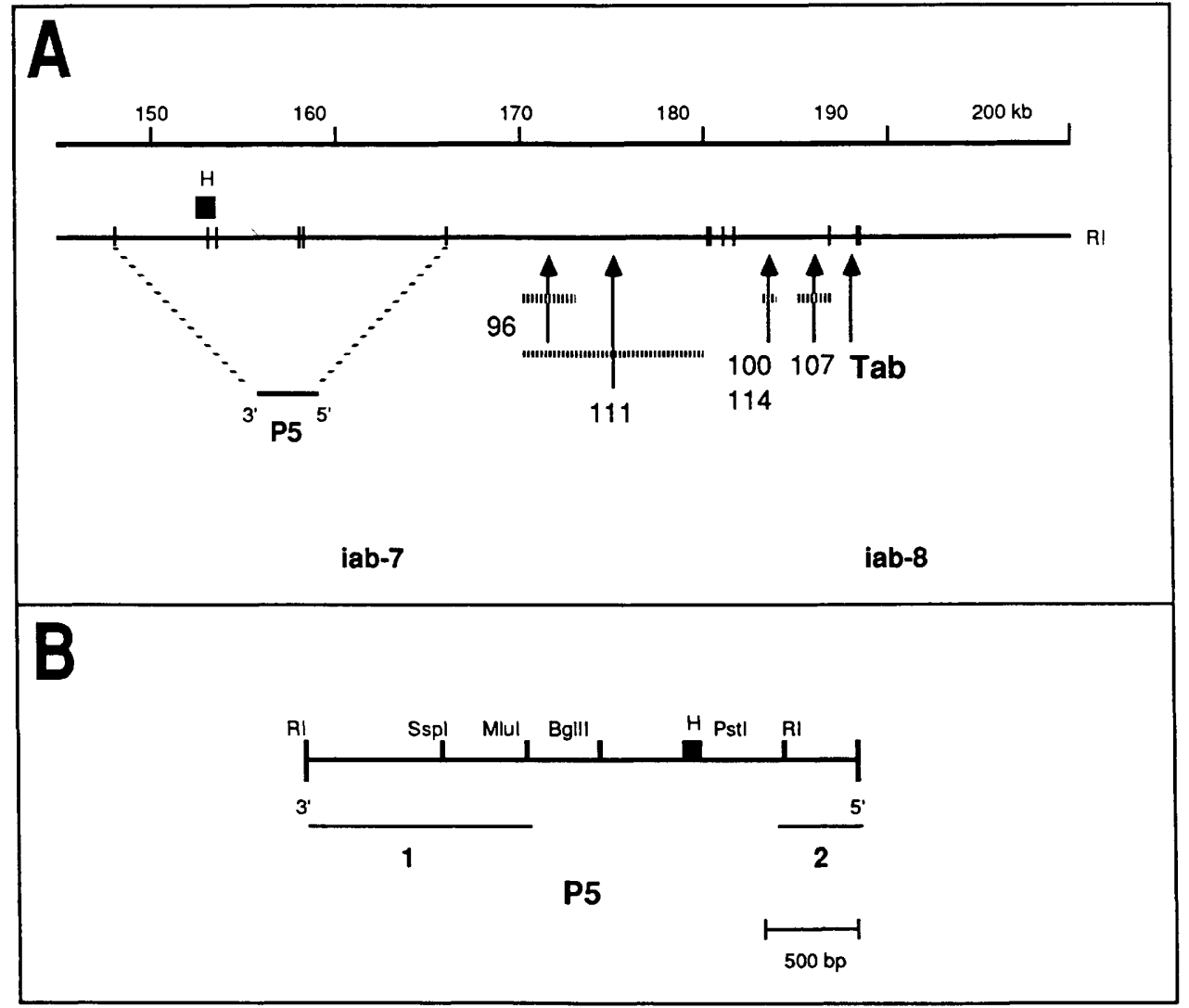

Figure 7. DNA maps of mutant lesions, of the P5 cDNA, and the restriction map of P5 cDNA. (A) The upper horizontal line represents the right end of the BX-C DNA walk. The coordinates show the distance in kilobases from the starting point of the BX-C DNA walk (see Bender et al. 1983a; Karch et al. 1985). The middle line shows the wild-type (Canton S) composite DNA map for the EcoRI restriction enzyme sites. The vertical arrows indicate the location of breakpoints of chromosomal rearrangements. Hatched horizontal lines indicate the amount of uncertainty in the position of those breakpoints as identified by DNA blot hybridization. The dotted line indicates the span of genomic DNA sequence which shows homology to the iab-7 cDNAs by DNA blot hybridization. The exact boundaries of the $i a b-7$ and $i a b-8$ regions have not yet been determined. $|B|$ Restriction map of P5 cDNA. The restriction enzyme fragments marked 1 and 2 were used to construct probes for DNA blot hybridization studies to determine the orientation of the cDNA relative to wild-type genomic DNA. Fragment 1 was used to construct probes for in situ hybridization to sections (see text) and to imaginal discs (see Figs. 8 and 9). (H) Homeo box.

$+153 \mathrm{~kb}$ as a probe, they were able to detect a complex set of transcripts in 6- to 12-hr embryonic poly $(\mathrm{A})^{+} \mathrm{RNA}$ ranging in size from 1 to $4.4 \mathrm{~kb}$. On the basis of their results we chose a genomic DNA fragment from +153 to $+155 \mathrm{~kb}$ as a probe to screen cDNA libraries for $i a b-7$ cDNA clones. We screened two $\lambda$ gt $10 \mathrm{cDNA}$ libraries (Kornberg et al. 1985) that had been constructed from 3to 12 -hr embryonic and $5.5-$ to 7.5 -day early pupal poly $(A)^{+}$RNA. Approximately $1 \times 10^{6}$ recombinant phage were screened from each library. We obtained seven cDNA clones (five embryonic and two pupal) which have inserts ranging in size from $1.5 \mathrm{~kb}$ to $3.0 \mathrm{~kb}$. When the seven cDNA clones are used individually as hybridization probes to the wild-type genomic BX-C DNA, they show homology to restriction fragments spanning $17 \mathrm{~kb}$ from +148 to +166 . Since the cDNA clones are similar at this level of sensitivity we have used the pupal cDNA clone with the largest insert /clone P5) for a detailed characterization. This cDNA is specific for the $i a b-7$ region by two criteria: (1) It hybridizes to salivary gland chromosomes only at position $89 \mathrm{E}$, and (2) under high-stringency blot hybridization conditions, it does not hybridize to homeo box-containing sequences from Ubx or iab-2 (data not shown). Employing the synthetic RI restriction sites used to insert the cDNA into $\lambda$ gt10, we subcloned the cDNA into the plasmid Puc 18. The Puc 18 P5 plasmid was used for all further studies.

We assigned a $5^{\prime} 3^{\prime}$ orientation for $i a b-7$ cDNA P5 based on three pieces of evidence: the $5^{\prime}$ GC tail (added during the construction of the cDNA library) was identified by sequencing; the cDNA was aligned on the BX-C DNA map using both ends of the cDNA as separate hybridization probes to the genomic sequences; and finally, the orientation of the homeo boxes of $U b x, i a b-2$, and iab-7 was known to be identical by heteroduplex mapping (Karch et al. 1985). Because the cDNA is only 3 $\mathrm{kb}$ in length and yet it hybridizes to genomic DNA fragments spanning $17 \mathrm{~kb}$, we can conclude that the $i a b-7$ gene must contain one or several introns. A restriction map for cDNA P5 is shown in Figure 7B. 


\section{In situ hybridization to imaginal discs}

We have used a $1.2-\mathrm{kb} M l u \mathrm{l} / E c o \mathrm{RI}$ restriction fragment from iab-7 cDNA P5 (labeled 1, Fig. 7B) which represents the 3 ' portion of the transcriptional unit as a probe for in situ hybridization to tissue sections from 8- to 24-hr Tab/ +, and from wild-type embryos and to wholemounted mass-isolated imaginal discs from $\mathrm{Tab} /+$, and from wild-type, third-instar larvae. In agreement with in situ hybridization experiments of Regulski et al. (1985), we detect $i a b-7$ transcripts in several segments, presumably, A5-A8 embryos of both Tab and wild-type (data not shown). We have not detected hybridization to segments anterior to A4 in Tab/ + embryos, but the expression in such segments could be limited to a small region so that a signal could easily have been missed.

Since the notum of T2 is derived from the "wing" discs (dorsal imaginal discs of T2) and since others (e.g., Akam 1983; Kornberg et al. 1985) have shown that transcripts can be detected in imaginal discs, $\mathrm{Tab} /+$ wing discs were analyzed for expression of $i a b-7^{+}$. Imaginal discs from wild-type and $T a b /+$ larvae were mass-isolated and probed with ${ }^{3} \mathrm{H}$-labeled purified DNA fragments from the iab-7 cDNA. We have used ${ }^{3} \mathrm{H}$-labeled hybridization probes rather than ${ }^{35} \mathrm{~S}$-labeled probes to eliminate possible artifacts in labeling of discs (as discussed in Kornberg et al. 1985).

Figure 8 shows the in situ hybridization patterns of wing discs from wild-type $\langle\mathrm{Mc} / \mathrm{Mc}\rangle$ ) and from $\mathrm{Tab}(\mathrm{Tab} /$ $M c)$ larvae, and genital discs from wild type (Canton S). The wing discs contain the cells that give rise not only to the wing, but also to the notum, postnotum, and several pleural plates on T2 (Fig. 9). Nineteen wing discs from wild-type (Canton S) animals were scored, and no labeling was observed. In one case, label was observed above background but the labeling was uniform over the entire disc. Of 45 unselected wing discs from a Tab/Mc mass-isolated disc preparation, 20 showed specific labeling above background; in every case such labeling was confined to the notal region of the wing disc (Fig. 8B,D and Fig. 9B). Twenty had no label above background in the notal or wing regions and presumably included $M c$ homozygotes and any $T a b / M c$ discs that were not oriented properly for detection of the short-ranged ${ }^{3} \mathrm{H}$ disintegrations (Fig. 8A,C). The remaining five were uniformly labeled over the entire disc. The restricted labeling to the notum and not to the wing portion of the disc supports the conclusion that the Tab phenotype results from an $i a b-7$ RNA or a modified $i a b-7$ RNA being abnormally regulated so that it becomes overexpressed in a spatially restricted manner in the thorax.

Figure 8, E and F, shows the in situ hybridization patterns of genital discs derived from wild-type flies. The genital discs give rise to the internal genitalia, external genitalia, and analia. Genital discs derived from $\mathrm{Tab} /+$ larvae reveal the same patterns of labeling as those from wild-type larvae (data not shown). Two distinct patterns of labeling of genital discs are observed; namely, grains completely covering the disc (Fig. 8E) and grains concentrated in a broad band bordering unlabeled regions of the disc (Fig. 8F). These different patterns of labeling may be

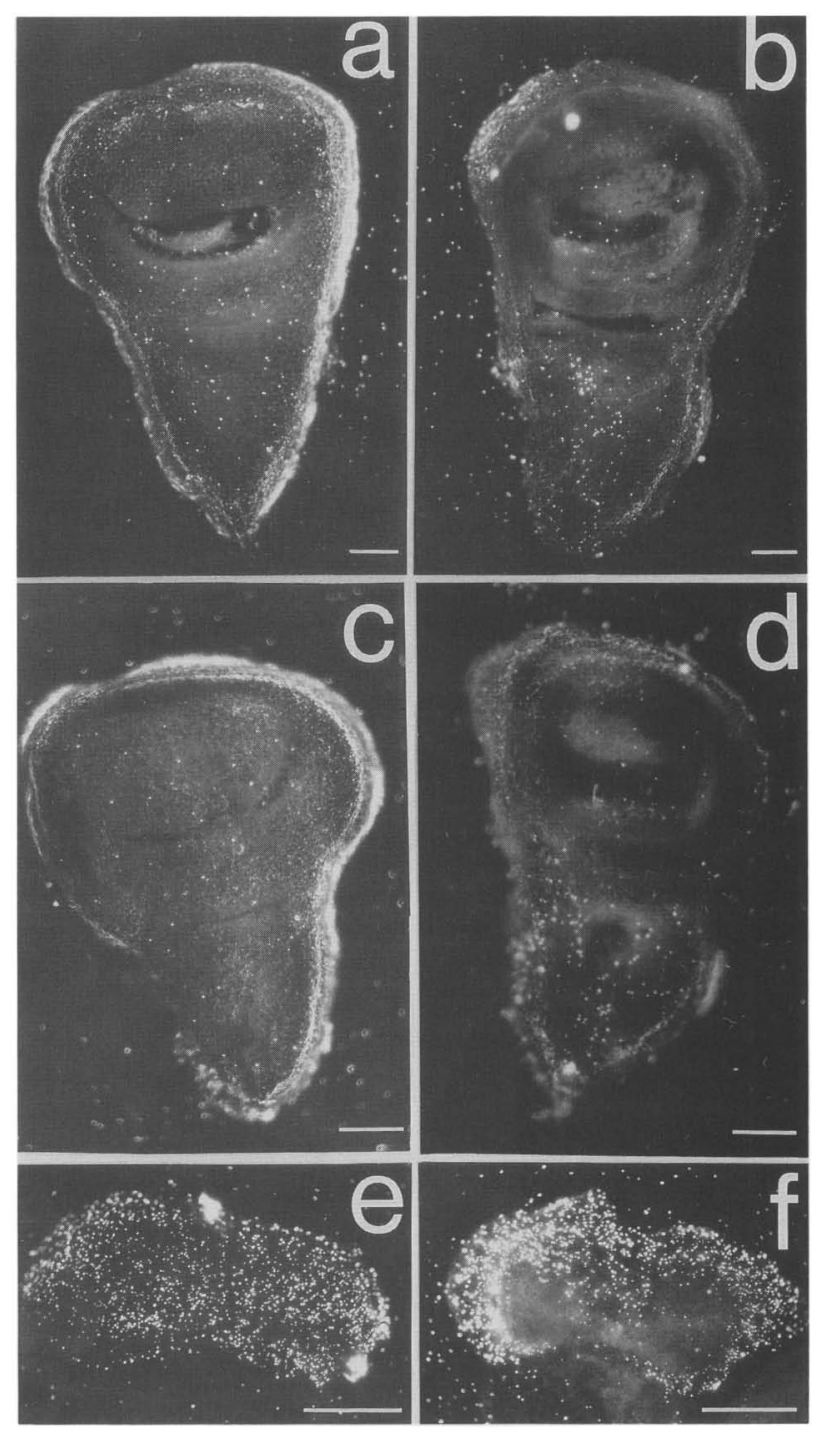

Figure 8. Localization of $i a b-7$ transcripts in imaginal discs. Dark-field photomicrographs after autoradiography of imaginal discs hybridized in situ with a ${ }^{3} \mathrm{H}$-labeled probe. $(A)$ An example of a wild-type $(\mathrm{Mc} / \mathrm{Mc})$ wing disc showing typical grain distribution that is not significantly different from that found in the background. $(B)$ An example of a $T a b(T a b / M c)$ wing disc with significant clustering of grains in the notal but not the wing region of the disc. (C) Another example of a typical wild-type $(M c / M c)$ wing disc. (D) Another example of the typical pattern of labeling of a $T a b / M c$ disc with significant labeling again clustered over the notal but not the wing region. $(E)$ Wild-type (Canton S) genital disc with dense distribution of grains over the entire disc. $\{F \mid$ Wild-type (Canton S) genital disc with grains densely clustered primarily at the edge of the disc. Bar, 0.02 $\mathrm{mm}$.

the result of differences in male and female genital disc structure (Dubendorfer and Nothiger 1982) or differences in the sidedness of the discs (Ursprung and Schabtach 1968). Using electron microscopy to analyze a parasagittal section of a male genital disc, Ursprung and Schabtach (1968) found that half way between the median and lateral tip of the disc the epithelium on one 

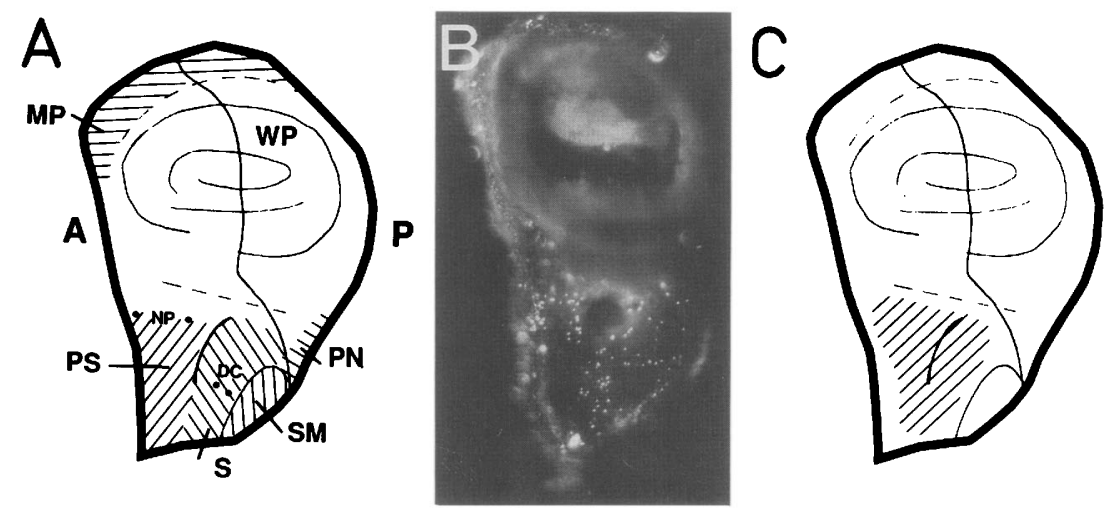

Figure 9. Localization of $i a b-7$ transcripts in $T a b$ wing discs in relation to the wing disc fate map. $(A)$ Fate map of the wing disc $($ after Bryant 1975). The regions of the wing disc which give rise to the thoracic as opposed to wing tissue are marked with hatched lines. The positions of two sets of bristles are shown by the filled circles. (A) Anterior; (P) posterior; (DC) dorsocentral bristles (cf. Fig. 3); (MP) mesopleura; (NP) notopleural bristles; (PN) postnotum; (PS) prescutum; (S) scutum; (SM) scutellum; (WP) wing pouch. (B) $\mathrm{Tab} / \mathrm{Mc}$ wing disc (enlargement of Fig. $8 \mathrm{~B}$ ) showing grain clustering over the notal but not the wing region. $(\mathrm{C})$ Composite diagram of a $\mathrm{Tab} / \mathrm{Mc}$ wing disc. The hatched lines within the notal portion of the disc indicate the common area over which grains are found to be clustered in Tab/Mc wing discs.

side of the disc is one cell layer thick and on the opposite side is at least two layers thick. In the latter case, the thickness may be great enough to prevent most ${ }^{3} \mathrm{H}$ disintegrations from being detected, or nonuniform $i a b-7$ expression may be involved.

\section{Discussion}

\section{Dominant phenotype of $\mathrm{Tab}$}

In $\mathrm{Tab} /+$ animals abdominal tergite-like tissue in the notum appears to replace thoracic tissue rather than being additional to it. Apparently, a group of notal cells, possibly clonal in origin, takes on characteristics of tergite tissue. In the thorax of $\mathrm{Tab} /+$ animals, the notal stripes are assumed to represent A6-like or A7-like tergite cuticle. Since the abdominal patches that arise in $\mathrm{A} 1-\mathrm{A} 6$, inclusive, can be most simply interpreted as resulting from a transformation to an A7 level of development in the dorsal ectoderm of each segment from T2-A6, inclusive, we conclude that the notal stripes are A7-like rather than A6-like. The aggregation of transformed A7-like tissue in well-defined stripes in the $\mathrm{Tab} /+$ thorax may reflect a clonal origin of the transformed tissue; if nonclonal in origin, then the striping pattern may be related to the tendency of dissociated imaginal disc cells with different developmental fates to sort out and reaggregate in accord with those fates (Garcia-Bellido and Lewis 1976). Whether Tab is active in dorsal T3 is indeterminate since in Diptera the notum of $\mathrm{T} 3$ is all but obliterated.

Roseland and Schneiderman (1979) find that the bulk of each hemitergite arises from a nest of histoblast cells that number 15-16 at the start of pupal life. Madhavan and Madhavan (1980) find that these cells undergo eight divisions before differentiating into a hemitergite and estimate that the entire tergite contains approximately 9000 cells. The size of the patches of A7-like tergite cuticle in $\mathrm{Tab} /+$ abdomens suggests that perhaps only one cell, or a few, of the initial nest are involved in producing each patch.

The notum of $\mathrm{T} 2$ arises from a pair of wing discs, each of which arises from a small cluster of cells that undergo some nine divisions to produce approximately 22,000 cells (Ripoll 1972). Thus, the ratio of the number of notal cells to the number in one of the major tergites (namely A2-A5) is very approximately 2.5 . This differential between cell number in the wing disc versus the number in the histoblast nest possibly accounts for the finding that the area of the two sets of $T a b$ stripes combined is much larger than that occupied by the average amount of $i a b-7-$ like tissue that arises in patches on a given tergite of the abdomen.

There is a striking precedence for such differential growth rates of the same type of tissue in the case of another dominant mutant in the complex, $C b x$, which produces a haltere-wing by transforming the wing toward haltere. As Morata and Garcia-Bellido (1976) have shown, more haltere tissue can be found in the halterewing of $\mathrm{T} 2$ than is ever found in the haltere in its normal location in T3. In this case ectopic overexpression of $\mathrm{Ubx}^{+}$in $\mathrm{T} 2$ is assumed to be responsible for the transformation of wing tissue to haltere tissue (T2 toward T3), and a higher rate of cell proliferation in wing than in haltere discs is assumed to account for the excessive amount of haltere tissue in the haltere-wing of T2.

We do not understand why the stripes arise at right angles to the abdominal tergites and why there are two sets of stripes instead of one. The invariance of the notal pattern may be related to the tendency of cells of different fates to sort out and then aggregate in accord with those fates (Garcia-Bellido and Lewis 1976). The presence on the Tab notum of two sets of stripes (or actually three sets if the outer divided stripe represents separate units of the pattern/ of tergite-like tissue instead of a single strip of such tissue may be indicative of different groups of tergite cells which in the environment of the 
notal cells of the imaginal disc are set apart as two (or three) separate islands of cells that ultimately become the stripes.

An explanation is needed for the striking sexual dimorphism in the striped pattern of the $T a b /+$ thorax if only A7 cuticle is involved. Animals that have only one dose of BX-C have rudimentary A7 tergites that are solidly pigmented black; whereas the A7 tergite in females, although reduced in size compared with that of A6, still contains a small light tan area as well as a black-pigmented area. Thus, A7, as well as A5 and A6, is sexually dimorphic. Therefore, we assume that the genetic controls that establish sexual dimorphism in the A5, A6, and A7 tergites of wild-type and $\mathrm{Tab} /+$ animals are operative in $\mathrm{T} 2$, just as they are operative in other thoracic regions such as $\mathrm{T} 1$, where the leg bears a sexcomb in males only.

We cannot completely rule out the possibility that other genes of the BX-C besides $i a b-7^{+}$must also be ectopically expressed in $\mathrm{T} 2$ before the $T a b$ pattern of striping can be expressed. Direct probing of the wing discs with probes derived from such regions of the complex has not been carried out. Although our Tab revertant analyses have failed to uncover deletions or inactivations of BX-C genes other than those involving the $i a b-7$ and $i a b-8$ regions, the number of revertants obtained is too few to exclude the possibility that an inactivation of $i a b-2$, for example, would lead to a loss of the striping pattern.

\section{Recessive phenotype of Tab}

The recessive phenotype of $T a b$ is a complex one. In addition to a recessive lethal effect from the inversion $T a b$ breakpoint in 90D, which appears to be without any detectable segmental transformations, there is a recessive lethal in $89 \mathrm{E}$, which appears from an analysis of embryonic phenotypes to be a weak to moderate inactivation of the $i a b-8$ function.

\section{cis-regulatory action of Tab}

A combination of cytogenetic and molecular results indicates that the dominant functional component of the $T a b$ phenotype represents a highly unusual case of overexpression of a BX-C gene. Overexpression of BX-C gene functions is known to occur by trans-regulation, as in the case of such mutants as $P c$ and $e s c$, and by cis-regulation, either as cis-overexpression (Lewis 1985) or, as in cases such as $C b x$, by dominant gain-of-function mutants. In the latter case, proof that $C b x$ acts in cis to cause strong overexpression of $\mathrm{Ubx}^{+}$(in T2) was obtained by deriving the double mutant, $C b x U b x$, as a crossover (Lewis 1955). Although the association of the $T a b$ mutant with the $T a b$ inversion, In $(3 R) T a b$, virtually precludes any attempt to derive the analogous double-mutant crossover (i.e., Tab combined with an $i a b-7$ loss-of-function mutant), the results of analyzing $T a b$ revertants strongly suggests that the observed overexpression of $i a b-7^{+}$in the $T a b$ mutant is a cis effect.
The overexpression of $i a b-7$ appears to be limited to only a fraction of the cells making up the notum or a tergite, in the sense that only stripes of A7-like cuticle appear on the notum and only patches of such cuticle appear on the tergites of $\mathrm{Al}-\mathrm{A} 6$, inclusive.

In the $T a b$ mutation the coding sequence of the $i a b-7$ gene appears not to be altered; instead, the small inversion associated with $T a b$ presumably results in changes in the upstream region of $i a b-7$ that somehow cause that gene to be ectopically overexpressed in cis. Preliminary studies show that the iab-7 gene has multiple transcripts with stage-specific differential splice patterns $(S$. Celniker and E. Lewis, unpubl.). The conditions that are necessary and sufficient for such overexpression remain to be determined. One possibility is that the Tab mutation results in altering only one or two of the stage-specific transcripts.

Analysis of revertants of the dominant phenotype of $T a b$ requires an understanding of how the BX-C is organized in the $\operatorname{In}(3 R) \mathrm{Tab}$ chromosome. The proximal 89E/90D juncture of that inversion brings the iab-7 region, and possibly a portion of the iab-8 regions as well, next to sequences in $90 \mathrm{D}$; as a result a portion at least of the $i a b-8$ region has been removed from $i a b-7$ and brought next to $90 \mathrm{D}$ sequences at the distal $89 \mathrm{E} / 90 \mathrm{D}$ junction. The 12 revertants that disrupt the proximal junction bring about reversion of $T a b$ by two mechanisms; one group (Class II and Class III) made up of five revertants, inactivate the $i a b-7$ function, and therefore presumably prevent that function from being overexpressed; the other group (Class I) made up of seven revertants, disrupts the proximal junction in such a way that the abnormal cis-regulation of $i a b-7^{+}$is abolished without disturbing the normal cis-regulation of that gene. As expected, both classes of revertants retain a recessive loss-of-function of $i a b-8$ that was present in the original In(3R)Tab chromosome from which, of course, the revertants were derived; in seven of the revertants the new breakpoint resulted in a more extreme loss of $i a b-8$ function than that present in the original $T a b$ chromosome.

\section{Tissue expression of iab-7}

The results of probing imaginal discs of $T a b /+$ for $i a b-7$ transcript expression support the foregoing interpretation of the dominant $T a b$ phenotype. In these experiments the genital discs provided a built-in control. Such discs are believed to be derived from segments $A 8$ and A9, which give rise to internal and external genitalia, and A10, which gives rise to analia. Since wild-type, as well as $\mathrm{Tab} /+$, genital discs gave excellent hybridization with the $i a b-7$ probe, $i a b-7$ is evidently active at least in segments A8 and A9, as well as in A7. Such hybridization would be in accord with the rule that once a gene of the BX-C becomes derepressed it tends to remain derepressed in more posterior segments. This rule has been verified for the distribution of $U b x$ transcripts in embryonic tissues, except that in wild type the extent of expression of those transcripts in more posterior seg- 
ments tends to diminish (Akam 1983; White and Wilcox 1984; Beachy et al. 1985). In the absence of genes in the abdominal portion of the complex, the extent of $U b x$ transcript expression does not diminish posteriorly, at least through segment A8 (parasegment 13) (Struhl and White 1985). The rule has also been verified for $i a b-7$ itself in embryonic tissues by Regulski et al. (1985), using an iab-7 homeo box-containing genomic DNA fragment, and by us, using a DNA fragment that does not contain the homeo box, from an iab-7 cDNA.

\section{Conclusions}

1. The $T a b$ phenotype is the result of misregulation of the iab-7 gene. Thus, molecular studies indicate that iab-7 transcripts are detectable in the notal region of wing discs of $\mathrm{Tab} /+$ but not wild-type wing discs. That both $\mathrm{Tab} /+$ and wild-type animals show strong expression of $i a b-7$ transcripts in genital discs indicates that $T a b$ retains the normal expression of $i a b-7$ in the terminal regions of the body at the same time that it causes ectopic expression of those transcripts in a highly constant and highly specific pattern in the thorax and a variable patch-like expression in the abdominal tergites, $\mathrm{A} 1-\mathrm{A} 6$, inclusive.

2. The mechanism by which $T a b$ causes misregulation of iab-7 is not known but might involve: (1) Alteration in cis-regulatory sequences upstream to the $i a b-7$ gene as the result of the $89 \mathrm{E} / 90 \mathrm{D}$ inversion junction in that region; or (2) the juxtaposition of iab-7 to cis-regulatory sequences from 90D, which in turn create the new ectopic tissue distribution of transcripts.

3. Mutants of the Tab type provide useful tools for studying ectopically expressed transformations of cells and tissues, especially when expressed in regions such as the notum of $\mathrm{T} 2$ that have differentially high rates of cellular proliferation.

\section{Experimental procedures}

\section{Mutant descriptions}

Descriptions of standard mutants used in this paper can be found in Lindsley and Grell (1968) or more recent BX-C mutants in Lewis (1978), except for the following: iab-7 alleles $D 3$, $D 6, D 14, D 15, D 16,297,380$, and 65 (Karch et al. 1985); Sab (Sakonju et al. 1984); Uab (Lewis 1981); Dp(3:3)P5 (Duncan and Lewis 1982); $D p(3: 1) 68$ (Lewis 1985); TM12 (carrying multiple inversions, $S b, T b$, and $D p(3) 462) ; T b$ (Auerbach cited in Craymer 1980).

\section{Induction and recovery of revertants}

Revertants of the dominant mutant $T a b$ were obtained from two different genetic screens. Males $p^{p} M c p$ Sab Tab/ bxd Mcp Sab Mc were irradiated with $4000 \mathrm{r}$. In screen 1 (Table 1) they were mated to homozygous $s b d^{2} b x d$ females. Each putative revertant was then crossed to $S b D p(3 ; 3 \mid P 5 / D f(3) P 9$ to establish a stock. In screen 2 the irradiated males were mated to homozygous $D p(3: 1) 68$; $C b x U b x$ females, that were also homozygous for recessive markers, $y^{2}$ (yellow-2) and g1 (glass-3). The presence of $D p(3 ; 1) 68$ allows homozygous $U b x$ to survive and allowed revertants to be recovered that might otherwise have been sterile from loss of function in iab-7 and/or $i a b-8$.

\section{Cytology}

Tab revertant/TM6, Hu Tb males /where $T b$ is a dominant larval marker) were mated to $s b d^{2} b x d$ females and non- $T b$ $\left(T a b / s b d^{2} b x d\right)$ larvae were selected for polytene chromosome analysis. Haplosterile revertants were maintained in stock by balancing over a TM12 chromosome. Males of such stocks were mated to wild-type (Canton S) or $s b d^{2} b x d$ females and non- $T b$ larvae were selected for salivary gland chromosome analysis.

\section{Isolation and purification of DNA}

Purification of fly DNA followed the procedure of Bender et al. (1983b). Phage DNA and plasmid DNA were isolated as described by Snyder et al. (1982) and Fyrberg et al. (1980), respectively.

\section{DNA labeling and hybridizations}

32P-labeled nick-translated probes were synthesized according to the method of Mullins et al. (1981). Hybridization reactions for whole genome Southerns contained $1 \times 10^{6} \mathrm{dpm} / \mathrm{ml}$ and were performed as described by Rozek and Davidson (1983).

\section{Construction of the recombinant phage library}

DNA from adult $T a b$ flies was partially digested with $M b o I$ and sized, and the fractions containing DNA fragments $10-15 \mathrm{~kb}$ in length were ligated into purified arms of the lambda vector $\mathrm{J1}$ (Davis et al. 1980). The phage were subsequently packaged in vitro according to the method of Hohn and Murray (1977).

\section{Screening cDNA libraries}

Two $\lambda$ gt 10 cDNA libraries, 3- to 12 -hr embryos and 5.5- to 7.5day pupae, kindly provided by L. Kauvar (Poole et al. 1985), were screened by plaque hybridization according to the method of Benton and Davis (1977).

\section{Scanning electron microscopy}

Adult flies were briefly etherized and mounted on a specimen holder using metallic nail polish. The specimen holder with the flies was immediately placed in an ETEC Autoscan SEM. The flies were photographed operating the SEM between 10 and 20 kv.

\section{Preparation of embryos for cuticular analysis}

For temporary preparations late embryos and first-instar larvae were mounted in a drop of lactic acid/ethanol $(9: 1)$, a coverslip was added, and the slide was left overnight on a $42^{\circ} \mathrm{C}$ warming plate. For permanent preparations embryos were dechorinated, fixed, and cleared according to the procedure of Van der Meer (1977).

\section{Preparation of adults for cuticular analysis}

Adult flies were preserved, cleared, and mounted as described by Duncan (1982).

\section{In situ hybridization}

In situ hybridizations to polytene chromosomes were performed according to Pardue and Gall (1975). Probes were labeled with ${ }^{35} \mathrm{~S}$ or ${ }^{3} \mathrm{H}$. Tissue sections from embryos and in situ hybridizations were performed according to Hafen et al. (1983) 
without dechorionating the embryos. Probes were labeled with ${ }^{3} \mathrm{H}$.

\section{Whole-mount in situ hybridization in discs}

Mass-isolated discs from a Tab/Mc stock were prepared according to Eugene and Fristrom (1976). The Mc chromosome probably carries a duplication for the distal end of the complex and covers the dominant sterility of $T a b$. The $T a b / M c$ stock produces $T a b$ homozygotes which are embryonic lethal and $M c$ homozygotes which are pupal lethal. We verified that the ratio of $T a b / M c$ to $M c / M c$ larvae was approximately $2: 1$. As a result only $67 \%$ of the animals and therefore of the discs are expected to be of genotype Tab/Mc. Whole-mounted in situ hybridizations were performed essentially as described by Kornberg et al. (1985) with the following modification of the method of preparing the probes. DNA fragments were purified by lowmelting-temperature agarose (Rozek and Davidson 1983) and an aliquot was nick-translated with Polymerase 1 and five different concentrations of bovine pancreas DNase $1(2-16 \mathrm{ng} / \mu \mathrm{g})$ for $2 \mathrm{hr}$ at $14^{\circ} \mathrm{C}$ in the presence of $100 \mu \mathrm{Ci}$ of [32 $\left.\mathrm{P}\right] \mathrm{dCTP}$. The products were sized and the reaction that gave fragments in the range of 35-150 bp was repeated using $100 \mu \mathrm{Ci}$ of each of two $\left[{ }^{3} \mathrm{H}\right] \mathrm{dNTPs}$. Autoradiographic exposures were for $2-4$ weeks.

\section{Acknowledgments}

We are grateful to John Pollock for assistance with the in situ hybridization experiments to whole-mounted imaginal discs and tissue sections. We thank Seymour Benzer, Norman Davidson, and John-Paul Revel for use of their laboratory facilities; Welcome Bender, Ian Duncan, Charles Rozek, and Sarah Smolik-Utlaut for helpful discussions; Rollin Baker, Patrick Koen, and Josephine Macenka for excellent technical assistance; David Baker and Timothy Cloherty for isolating two of the Tab revertants; Welcome Bender and Marko Zalokar for critically reviewing the manuscript; and Rollin Baker, Katie Patterson, and Renee Thorf for assistance in preparing the manuscript.

This work was supported by a postdoctoral fellowship from the National Institutes of Health to S.C. (GM09469-01) and by research grants to E.B.L. from the National Institutes of Health (HD-06331), the American Cancer Society (00543), and the March of Dimes (1-1029). This project was supported in part by the Biomedical Research Support Program's Grant RR07003 of the Division of Research Resources, National Institutes of Health.

\section{References}

Akam, M.E. 1983. The location of Ultrabithorax transcripts in Drosophila tissue sections. EMBO I. 2: 2075-2084.

Awad, A.A.M., J. Gausz, H. Gyurkovics, and A. Parducz. 1981. A new homeotic mutation, SGA62, in Drosophila melanogaster. Acta Biol. Acad. Sci. Hung. 32: 219-228.

Beachy, P.A., S.L. Helfand, and D.S. Hogness. 1985. Segmental distribution of bithorax complex proteins during Drosophila development. Nature 313: 545-551.

Bender, W., M. Akam, F. Karch, P.A. Beachy, M. Peifer, P. Spierer, E.B. Lewis, and D. Hogness. 1983a. Molecular genetics of the bithorax complex in Drosophila melanogaster. Science 221: 23-29.

Bender, W., P. Spierer, and D.S. Hogness. 1983b. Chromosomal walking and jumping to isolate DNA from the Ace and rosy loci and the bithorax complex in Drosophila melanogaster. J. Mol. Biol. 168: 17-33.

Benton, W.D. and R.W. Davis. 1977. Screening gt recombinant clones by hybridization to single plaques in situ. Science 196: $180-182$.

Bryant, P.J. 1975. Pattern formation in the imaginal wing disc of Drosophila melanogaster: Fate map, regeneration, and duplication. I. Exp. Zool. 193: 49-78.

- 1978. Pattern formation in imaginal discs. In The genetics and biology of Drosophila (ed. M. Ashburner and T.R.F. Wright/, pp. 230-345. Academic Press, New York.

Celniker, S.E. and E.B. Lewis. 1984. Transabdominal: A new dominant mutant in the bithorax gene complex (BX-C) of Drosophila melanogaster. Genetics 107: s17.

Craymer, L. 1980. New mutants-D. melanogaster. Dros. Inf. Serv. 55: 199.

Davis, R.W., D. Botstein, and J.R. Roth. 1980. Advanced bacterial genetics. Cold Spring Harbor Laboratory, Cold Spring Harbor, New York.

Dubendorfer, K. and R. Nothiger. 1982. A clonal analysis of cell lineage and growth in the male and female genital disc of Drosophila melanogaster. Wilhelm Roux's Arch. 191: 4255.

Duncan, I.M. 1982. Polycomblike: A gene that appears to be required for the normal expression of the bithorax and Antennapedia gene complexes of Drosophila melanogaster. Genetics 102: 49-70.

Eugene, O.M. and J.W. Fristrom. 1976. The mass isolation of imaginal discs. In The genetics and biology of Drosophila (ed. M. Ashburner and T.R.F. Wright), vol. 2a, pp. 121-126. Academic Press, New York.

Fyrberg, E.A., K.L. Kindle, N. Davidson, and A. Sodja. 1980. The actin genes of Drosophila: A dispersed multigene family. Cell 19: 365-378.

Garber, R.L., A. Kuroiwa, and W.J. Gehring. 1983. Genomic and cDNA clones of the homeotic locus Antennapedia in Drosophila. EMBO J. 2: 2027-2034.

Garcia-Bellido, A. and E.B. Lewis. 1976. Autonomous differentiation of homoeotic bithorax mutants of Drosophila melanogaster. Dev. Biol. 48: 400-410.

Hafen, E., M. Levine, R.L. Garber, and W.J. Gehring. 1983. An improved in situ hybridization method for the detection of cellular RNAs in Drosophila tissue sections and its application for localizing transcripts of the homeotic Antennapedia gene complex. EMBO I. 2: 617-623.

Hohn, B. and K. Murray. 1977. Packaging recombinant DNA molecules in bacteriophage particles in vitro. Proc. Natl. Acad. Sci. 74: 3259-3263.

Karch, F., B. Weiffenbach, M. Peifer, W. Bender, I. Duncan, S. Celniker, M. Crosby, and E.B. Lewis. 1985. The abdominal region of the bithorax complex. Cell 43: 81-96.

Kaufman, T., R.A. Lewis, and B.T. Wakimoto. 1980. Cytogenetic analysis of chromosome 3 in Drosophila melanogaster: The homeotic gene complex in polytene chromosome interval 84AB. Gene 904: 115-133.

Kornberg, T., I. Siden, P. O'Farrell, and M. Simon. 1985. The engrailed locus of Drosophila: In situ localization of transcripts reveals compartment-specific expression. Cell 40: $45-53$.

Kuhn, D.T., D.R. Woods, and D.J. Andrews. 1981. Analysis of a new homeotic mutation (iab-2) within the bithorax complex in Drosophila melanogaster. Mol. Gen. Genet. 181: 82-86.

Lewis, E.B. 1955. Some aspects of position pseudo allelism. Am. Nat. 89: 73-89.

- 1968. Genetic control of developmental pathways in Drosophila melanogaster. Proc. Int. Congr. Genet. 2: 96-97. Science Council of Japan, Tokyo.

1978. A gene complex controlling segmentation in Drosophila. Nature 276: 565-570. 
1981. Developmental genetics of the bithorax complex. ICN-UCLA Symp. Mol. Cell. Biol. 23: 189-208.

1985. Regulation of the genes of the bithorax complex in Drosophila. Cold Spring Harbor Symp. Quant. Biol. 50: $155-164$.

Lindsley, D.L. and E.H. Grell. 1968. Genetic variations of Drosophila melanogaster. Carnegie Institution of Washington, Publ. No. 627.

Lohs-Schardin, M., C. Cremer, and C. Nusslein. 1979. A fate map for the larval epidermis of Drosophila melanogaster: Localized cuticle defects following irradiation of the blastoderm with an ultraviolet laser microbeam. Dev. Biol. 73: $239-255$.

Madhavan, M.M. and K. Madhavan. 1980. Morphogenesis of the epidermis of adult abdomen of Drosophila. I. Embryol. Exp. Morph. 60: 1-31.

Martinez-Arias, A. and P. Lawrence. 1985. Parasegments and compartments in the Drosophila embryos. Nature 313: 639-642.

Morata, G. and A. Garcia-Bellido. 1976. Developmental analysis of some mutants of the bithorax system of Drosophila. Wilhelm Roux's Arch. 179: 125-143.

Mullins, J.I., J.W. Casey, M.O. Nicolson, K.B. Burck, and N. Davidson. 1981. Sequence arrangement and biological activity of cloned feline leukemia virus proviruses from a virus producing human cell line. J. Virol. 38: 688-703.

Nüsslein-Volhard, C. 1979. Maternal effect mutations that alter the spatial coordinates of the embryos of Drosophila melanogaster. In Determinants of spatial organization (ed. S. Subtelny and I.R. Konigsberg), pp. 185-211. Academic Press, New York.

Nüsslein-Volhard, C. and E. Wieschaus. 1980. Mutations affecting segment number and polarity in Drosophila. Nature 287: 795-801.

Pardue, M. and J.G. Gall. 1975. Nucleic acid hybridization to the DNA of cytological preparations. Methods Cell Biol. 10: $1-16$.

Poole, S.J., L.M. Kauvar, B. Drees, and T. Kornberg. 1985. The engrailed locus of Drosophila: Structural analysis of an embryonic transcript. Cell 40: 37-43.

Postlewaite, J.H., P.J. Bryant, and G. Schubiger. 1972. The homoeotic effect of "Tumorous Head" in Drosophila melanogaster. Dev. Biol. 29: 337-342.

Regulski, M., K. Harding, R. Kostriken, F. Karch, M. Levine, and W. McGinnis. 1985. Homeo box genes of the antennapedia and bithorax complexes of Drosophila. Cell 43: 7180.

Ripoll, P. 1972. The embryonic organization of the imaginal wing disc of Drosophila melanogaster. Wilhelm Roux's Arch. 169: 200-215.

Roseland, C.R. and H.A. Schneiderman. 1979. Regulation and metamorphosis of the abdominal histoblasts of Drosophila melanogaster. Wilhelm Roux's Arch. Devl. Biol. 186: 235265.

Rozek, C.E. and N. Davidson. 1983. Drosophila has one myosin heavy-chain gene with three developmentally regulated transcripts. Cell 32: 23-34.

Sakonju, S., E.B. Lewis, and D.S. Hogness. 1984. Genetic and molecular analyses of the abdominal region of the bithorax gene complex (BX-C) in Drosophila melanogaster. Genetics 107: s93.

Sanchez-Herrero, E., I. Vernos, R. Marco, and G. Morata. 1985. Genetic organization of Drosophila bithorax complex. $\mathrm{Na}$ ture 313: 108-113.

Scott, M.F., A.J. Weiner, T.I. Hazelrigg, B.A. Poliskey, Y. Pirotta, F. Scalenghe, and T.C. Kaufman. 1983. The molecular organization of the antennapedia locus of Drosophila. Cell 35: $753-776$.

Snyder, M., M. Hunkapillar, D. Yuen, D. Silvert, J. Fristrom, and N. Davidson. 1982. Cuticle protein genes of Drosophila: Structure, organization, and evolution of four clustered genes. Cell 29: 1027-1040.

Struhl, G. 1981. A gene product required for the correct initiation of segmental determination in Drosophila. Nature 293: $36-40$.

Struhl, G. and R.A.H. White. 1985. Regulation of the Ultrabithorax gene of Drosophila by other bithorax complex genes. Cell 43: 507-520.

Szabad, J., T. Schupbach, and E. Wieschaus. 1979. Cell lineage and development in the larval epidermis of Drosophila melanogaster. Dev. Biol. 73: 256-271.

Tiong, S., L.M. Bone, and J.R.S. Whittle. 1985. Recessive lethal mutations within the bithorax-complex in Drosophila. Mol. Gen. Genet. 200: 335-342.

Ursprung, H. and E. Schabtach. 1968. The fine structure of the male Drosophila genital disk during late larval and early pupal development. Wilhelm Roux's Arch. 160: 243-254.

Van der Meer, J.M. 1977. Optical clean and permanent wholemount preparation for phase-contrast microscopy of cuticular structures of insect larvae. Dros. Inf. Serv. 52: 160.

White, R.A.H. and M. Wilcox. 1984. Protein products of the bithorax complex in Drosophila. Cell 39: 163-171. 


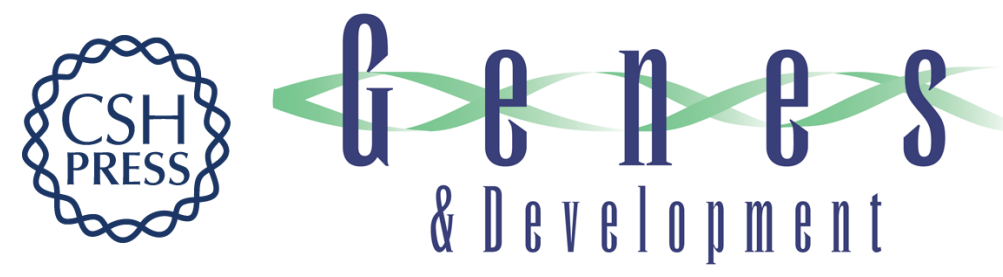

\section{Transabdominal, a dominant mutant of the Bithorax Complex, produces a sexually dimorphic segmental transformation in Drosophila.}

S E Celniker and E B Lewis

Genes Dev. 1987, 1:

Access the most recent version at doi:10.1101/gad.1.2.111

References This article cites 48 articles, 6 of which can be accessed free at:

http://genesdev.cshlp.org/content/1/2/111.full.html\#ref-list-1

License

Email Alerting Receive free email alerts when new articles cite this article - sign up in the box at the top Service right corner of the article or click here.

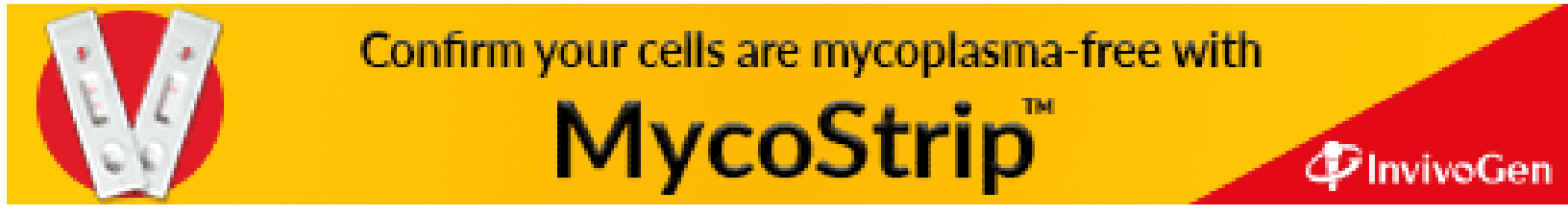

